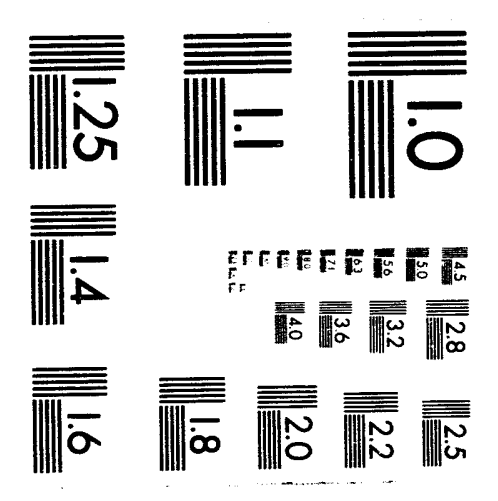



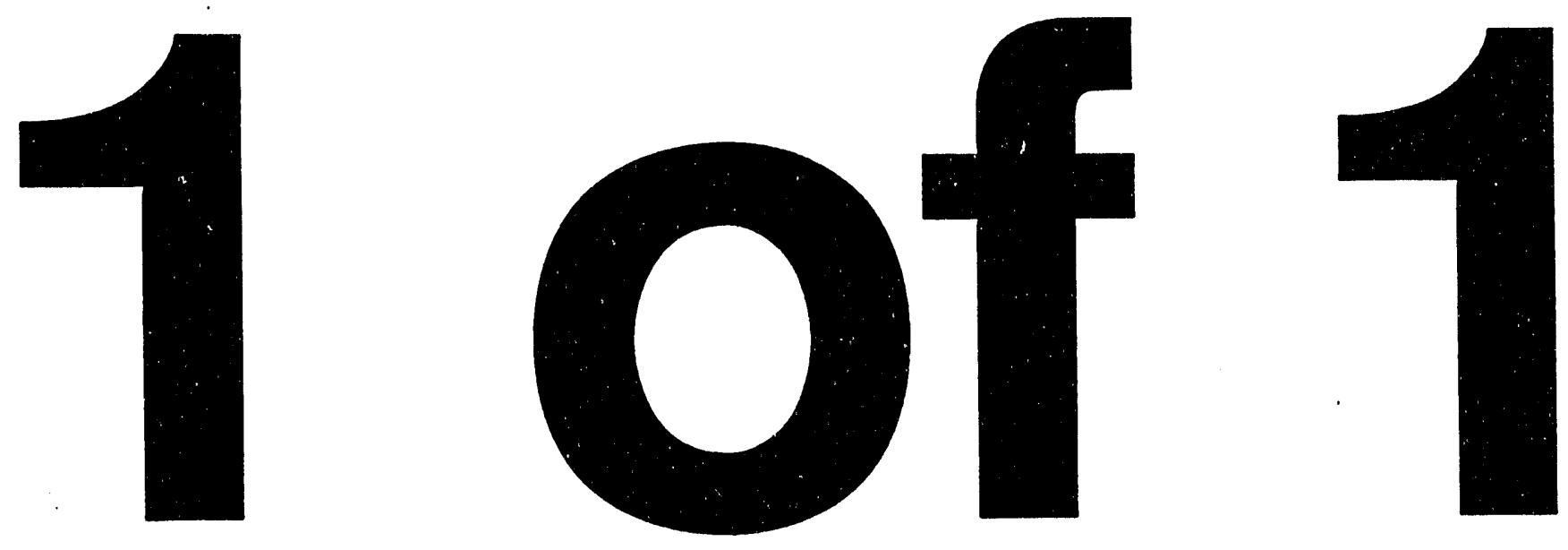


\title{
Selective Chelation and Extraction of Lanthanides and Actinides with Supercritical Fluids
}

R. D. Brauer

T. E. Carleson

J. D. Harrington

F. Jean

Hao Jiang

Yuehe Lin

C. M. Wai

Published January 1994

\author{
Idaho National Engineering Laboratory \\ EG\&G Idaho, Inc. \\ Idaho Falls, Idaho 83415
}

Prepared for the

U.S. Department of Energy 


\section{Selective Chelation and Extraction of Lanthanides and Actinides with Supercritical Fluids}

EGG-WTD-10993

Approved by

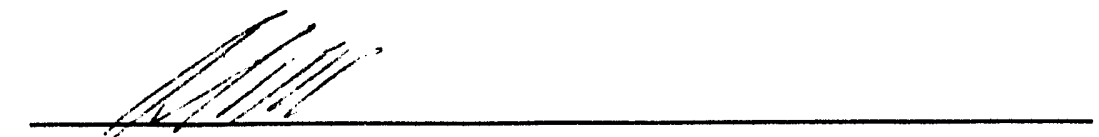

J. M. Beller, Project Manager

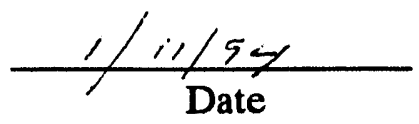

Demonstration, Testing, and Evaluation 


\begin{abstract}
This report is made up of three independent papers: (1) Supercritical Fluid Extraction of Thorium and Uranium with Fluorinated Beta-Diketones and Tributyl Phosphate, (2) Supercritical Fluid Extraction of Lanthanides with Beta-Diketones and Mixed Ligands, and (3) A Group Contribution Method for Predicting the Solubility of Solid Organic Compounds in Supercritical Carbon Dioxide. Experimental data are presented demonstrating the successful extraction of thorium and uranium using fluorinated beta-diketones to form stable complexes that are extracted with supercritical carbon dioxide. The conditions for extracting the lantinide ions from liquid and solid materials using supercritical carbon dioxide are presented. In addition, the Peng-Robison equation of state and thermodynamic equilibricm are used to predict the solubilities of organic solids in supercritical carbon dioxide from the sublimation pressure, critical properties, and acentric factor of the solid of interest.
\end{abstract}




\section{SUMMARY}

The University of Idaho through the U.S. Department of Energy's Office of Technology Development, Innovative Technology Development Program has evaluated the use of supercritical fluid extraction to remove lanthanides and actinides from soils. Past research at the University of Idaho showed that lariat crown ethers could be designed for selective chelation of the F-block elements. Once chelated, they could then be extracted with supercritical carbon dioxide. The research covered in this report includes evaluation of beta-diketones, mixed ligands, and fluorinated beta-diketones for extracting these elements.

This report is made up of three independent reports: (1) Supercritical Fluid Extraction of Thorium and Uranium with Fluorinated Beta-Diketones and Tributyl Phosphate, (2) Supercritical Fluid Extraction of Lanthanides with Beta-Diketones and Mixed Ligands, and (3) A Group Contribution Method for Predicting the Solubility of Solid Organic Compounds in Supercritical Carbon Dioxide. 


\section{CONTENTS}

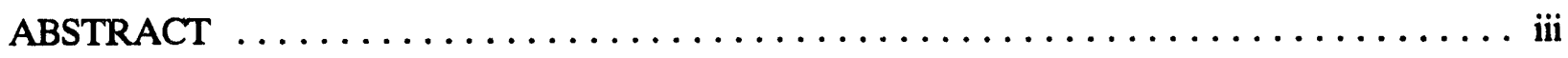

SUMMARY $\ldots \ldots \ldots \ldots \ldots \ldots \ldots \ldots \ldots \ldots \ldots \ldots \ldots \ldots \ldots \ldots \ldots \ldots \ldots$

INTRODUCTION $\ldots \ldots \ldots \ldots \ldots \ldots \ldots \ldots \ldots \ldots \ldots \ldots \ldots \ldots \ldots \ldots$

SUPERCRITICAL FLUID EXTRACTION OF THORIUM AND URANIUM WITH

FLUORINATED BETA-DIKETONES AND TRIBUTYL PHOSPHATE $\ldots \ldots \ldots \ldots \ldots$

SUPERCRITICAL FLUID EXTRACTION OF LANTHANIDES WITH

BETA-DIKETONES AND MIXED LIGANDS $\ldots \ldots \ldots \ldots \ldots \ldots \ldots \ldots \ldots \ldots$

A GROUP CONTRIBUTION METHOD FOR PREDICTING THE SOLUBILITIES

OF SOLID ORGANIC COMPOUNDS IN SUPERCRITICAL CARBON DIOXIDE 


\section{Selective Chelation and Extraction of Lanthanides and Actinides with Supercritical Fluids}

\section{INTRODUCTION}

The University of Idaho through the U.S. Department of Energy's Office of Technology Development, Innovative Technology Development Program has evaluated the use of supercritical fluid extraction to remove lanthanides and actinides from soils. Their past research showed that lariat crown ethers could be designed for selective chelation of the F-block elements. Once chelated, they could then be extracted with supercritical carbon dioxide. This report, which is a combination of three papers, includes the evaluation of beta-diketones, mixed ligands, and fluorinated beta-diketones for extracting these elements.

This report is made up of three independent papers: (1) Supercritical Fluid Extraction of Thorium and Uranium with Fluorinated Beta-Diketones and Tributyl Phosphate, (2) Supercritical Fluid Extraction of Lanthanides with Beta-Diketones and Mixed Ligands, and (3) A Group Contribution Method for Predicting the Solubility of Solid Organic Compounds in Supercritical Carbon Dioxide. Each of these papers have been submitted to a peer review journal for publication and are compiled in this report to document the results of the contract. 


\title{
Supercritical Fluid Extraction of Thorium and Uranium with Fluorinated Beta-Diketones and Tributyl Phosphate
}

\author{
C. M. Wal, Yuehe Lin, R. D. Brauer, F. Jean \\ Department of Chemistry \\ University of Idaho \\ Moscow, Idaho 83843
}

\section{INTRODUCTION}

Supercritical fluid extraction (SFE) of organic compounds from various matrices has been the subject of many studies ${ }^{1,2}$. The high diffusivity, low viscosity, and T-P dependence of solvent strength are some attractive properties which make supercritical fluids excellent candidates for removing organic compounds from solid materials. Carbon dioxide is a gas of choice for SFE due to its moderate critical constants, inertness, and availability in pure form. Recently, Wai and coworkers demonstrated that metal ions can be extracted by supercritical carbon dioxide containing a suitable chelating agent. For example, they reported that $\mathrm{Cu}^{2+}$ and $\mathrm{Hg}^{2+}$ can be extracted from solid materials by supercritical $\mathrm{CO}_{2}$ containing the fluorinated ligand lithium bis(trifluoroethyl) dithiocarbamate (LiFDDC) $)^{3,4}$. The negatively charged ligand (FDDC ${ }^{-}$) reacts with the metal ions to form neutral metal chelates which become soluble in supercritical $\mathrm{CO}_{2}$. The choice of the fluorinated ligand is based on the fact that the solubilities of metal-FDDC complexes in supercritical $\mathrm{CO}_{2}$ are significantly higher than the non-fluorinated analogues ${ }^{5,6}$. This in situ chelation-SFE technique may have important applications for preconcentration of trace metals from environmental samples and for treatment of metal contaminated wastes. The success of this new metal extraction technique for environmental applications depends largely on the effectiveness and availability of the ligand. LiFDDC is not commercially available and does not form stable complexes with certain groups of elements including the f-block elements. It was reported recently that trivalent lanthanide and uranyl ions can be extracted by supercritical $\mathrm{CO}_{2}$ containing the fluorinated beta-diketone, 2,2-dimethyl$6,6,7,7,8,8,8$-heptafluoro-3,5, octanedione (FOD) ${ }^{7}$. This report is significant because a number of fluorinated beta-diketones are available commercially and are known to form stable complexes with lanthanides and actinides. They are potential extractants for SFE of the f-block elements. SFE of actinides is of particular interesting because of its potential applications to nuclear waste analysis and management. This communication describes the conditions of extracting thorium and uranium from solid and liquid materials by supercritical $\mathrm{CO}_{2}$ containing different beta-diketones. In addition, the synergistic extraction of the actinides by mixed ligands involving beta-diketones and tributyl phosphate (TBP) in supercritical $\mathrm{CO}_{2}$ is also reported. Synergistic extraction using mixed ligands is another approach to improve the efficiencies of common ligands for actinide separation by SFE. Applications ol this new extraction technique for separation of the actinides from environmental samples are discussed. 


\section{EXPERIMENTAL SECTION}

The florinated beta-diketones were purchased from the Aldrich Chemical Company (Milwaukee, WI) and used without further purification. Uranyl $\left(\mathrm{UO}_{2}\right)^{2+}$ and $\mathrm{Th}^{4+}$ solutions were prepared from their nitrate salts obtained from Baker Chemical Co. and from Mallinckrodt, Inc. (St. Louis, MO), respectively. All other chemicals used were analytical-reagent grade. Filter papers used as the solid sample matrix were obtained from Whatman Ltd (Maidstone, England). Solid samples were prepared by spiking $10 \mu \mathrm{g}$ each of a mixture of $\mathrm{Th}^{4+}$ and $\left(\mathrm{UO}_{2}\right)^{2+}$ on pre-washed filter papers (Whatman 42 , $0.5 \mathrm{~cm} \mathrm{x} 2 \mathrm{~cm}$ in size, washed with Ultrex $\mathrm{HNO}_{3}$ and rinsed with deionized water). The spiked filter papers were allowed to air dry at a room temperature of $23^{\circ} \mathrm{C}$. Water samples were $0.05 \mathrm{M}$ $\mathrm{HAc} / \mathrm{LiAc}$ buffer solution ( $\mathrm{pH}$ 6.5) containing $2.5 \mu \mathrm{g} / \mathrm{mL}$ each of $\mathrm{Th}^{4+}$, and $\left(\mathrm{UO}_{2}\right)^{2+}$. All experiments were performed with a lab-built SFE apparatus. SFC-grade $\mathrm{CO}_{2}$ or $\mathrm{CO}_{2}$ with $5 \%$ (mole) methanol modifier (Scott Specialty Gases, Plumsteadville, PA) was delivered to the SFE system using a Haskel pump (Haskel Inc., Burbank, CA). The system pressure was monitored to \pm 5 psi using a Setra System (Acton, MA) pressure transducer. The extractor consisted of an inlet valve (SUPELCO, Bellefonte, PA) and an outlet valve connected to an extraction vessel. For the extraction of solid samples, a commercial extraction vessel (Dionex, Sunnyvale, CA) having a volume of $3.5 \mathrm{~mL}$ was used. The main body of the liquid extraction vessel was made from a stainless steel column $(0.75 \mathrm{~cm}$ i.d. and $14 \mathrm{~cm}$ in length, Alltech) and the infittings were obtained from Swagelok (Seattle, WA). The vessel was modified for use with liquid samples in the same manner as reported earlier by Hendrick et al. ${ }^{8}$. The stainless steel inlet and outlet tubes were 0.02 in. internal diameter and extended to within $1 \mathrm{~cm}$ of the top and bottom of the vessel. A $3.5 \mathrm{~mL}$ stainless steel high pressure cylinder containing TTA as chelating agent was connected upstream of the liquid extraction vessel. The ligand cylinder and the extraction vessel were placed in an oven with temperature controlled to $\pm 0.1^{\circ} \mathrm{C}$ by an OMEGA (Stamford, CT) CN9000A temperature controller. A fusedsilica tubing (Dionex, $50 \mu \mathrm{m}$ i.d. and $20 \mathrm{~cm}$ in length) was used as the pressure restrictor for the exit gas. The SFE system allows static and dynamic extraction steps to be carried out by closing and opening of the inlet and outlet valves.

For solid sample extraction, a glass tube $(0.5 \mathrm{~cm}$ i.d. and $3 \mathrm{~cm}$ in length) was plugged at one end with a piece of glass wool, previously cleaned with Ultrex nitric acid. To the open end of the glass tube, a spiked filter sample was inserted. About $80 \mu$ moles of a beta-diketone ligand was introduced to the sample and the open end was plugged with a piece of clean glass wool. The sample tube was placed immediately into the extraction vessel and installed in the SFE oven. The temperature of the oven was set at $60^{\circ} \mathrm{C}$ and the cell was pressurized to $150 \mathrm{~atm}$. The chelation and the extraction processes were allowed to occur under a static SFE condition for 10 minutes. After than, the exit valve was opened and the sample was extracted and flushed under dynamic conditions for 10 minutes. The extraction conditions were adopted based on a previous study for the SFE of uranyl ions using FOD as an extractant ${ }^{7}$. When the dynamic extraction step was completed, the sample was removed from the SFE system and the filter paper was analyzed by a non-destructive neutron activation analysis (NAA). A standard filter paper containing the same amount of the actinide ions was irradiated and counted with the sample under identical conditions. The extraction efficiencies were calculated based on the amount of the thorium and uranium found in the filter paper before and after the extraction. 
For the extraction of the actinides from water, $4 \mathrm{~mL}$ of the spiked water sample were placed in the liquid extraction vessel. The water samples usually contained $2.5 \mu \mathrm{g} / \mathrm{mL}$ each of $\mathrm{Th}^{4+}$ and $(\mathrm{UO} 2)^{2+}$ with $\mathrm{pH}$ controlled by an acetate buffer. A certain amount of TTA (approximately $50 \mathrm{mg}$ ) was loaded in the ligand cylinder placed upstream from the liquid extraction vessel. The samples were extracted dynamically at $60^{\circ} \mathrm{C}$ and $150 \mathrm{~atm}$ for 20 minutes. When the extraction was completed, the sample was removed from the extraction vessel and analyzed by NAA. A standard solution containing $2.5 \mu \mathrm{g} / \mathrm{mL}$ each of thorium and uranium was irradiated and counted with the sample under identical conditions. The extraction efficiencies were calculated based on the amounts of thorium and uranium found in the aqueous solution before and after the extraction. The extracted $\mathrm{Th}^{4+}$ and $\left(\mathrm{UO}_{2}\right)^{2+}$ complexes in the fluid phase were collected in a glass vial containing $5 \mathrm{~mL}$ of chloroform. The solutes trapped in the chloroform solution were determined by back-extraction with $50 \% \mathrm{HNO}_{3}$ followed by NAA of the acid solution. The results were also used for recovery calculations.

All samples and standards were irradiated for $2 \mathrm{~h}$ in a $1 \mathrm{MW}$ TRIGAR nuclear reactor at a steady flux of $6 \times 10^{12} \mathrm{n} \mathrm{cm}^{-2} \mathrm{~s}^{-1}$. After irradiation, the samples were cooled for $24 \mathrm{~h}$ before counting. Each sample was counted for $100 \mathrm{~s}$ in a large-volume ORTEC $\mathrm{Ge}(\mathrm{Li})$ detector with a resolution (FWHM) of about $2.3 \mathrm{keV}$ at the $1332-\mathrm{keV}^{60} \mathrm{Co}$ peak. Uranium was determined by the $228 \mathrm{keV}$ gamma emitted during the decay of its daughter ${ }^{239} \mathrm{~Np}(2.36 \mathrm{~d})$. Neutron activation of ${ }^{232} \mathrm{Th}$ produces a short lived radioisotope ${ }^{233} \mathrm{Th}$ with a half life of 22.2 minutes. Its daughter product, ${ }^{233} \mathrm{~Pa}$ (27 days) further decays to ${ }^{233} \mathrm{U}$ with the emission of $311 \mathrm{keV}$ gamma which was used for quantitative determination of thorium. The detailed procedures of NAA are described elsewhere ${ }^{9}$.

\section{RESULTS AND DISCUSSION}

Beta-diketones are able to form complexes with metal ions through the enolate anions as shown by the following equilibria:

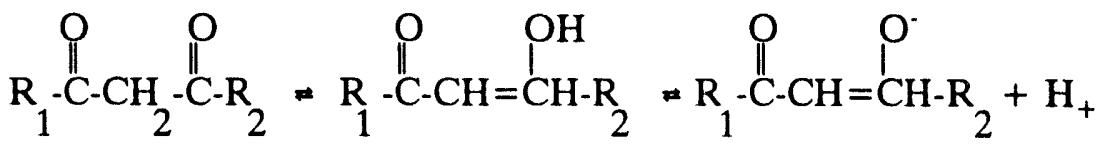

The following five beta-diketones were tested as ligands for the extraction of $\mathrm{TH}^{4+}$ and $\left(\mathrm{UO}_{2}\right)^{2+}$ in supercritical carbon dioxide: acetylacetone ( $A A, R_{1}=R_{2}=C_{3}$ ), trifluoroacetylacetone (TAA, $\mathrm{R}_{1}=\mathrm{CH}_{3}, \mathrm{R}_{2}=\mathrm{CF}_{3}$ ), hexafluoroacetylacetone ( $\mathrm{HFA}, \mathrm{R}_{1}=\mathrm{R}_{2}=\mathrm{CF}_{3}$ ), thenoyltrifluoroacetylacetone (TAA, $R_{1}=$ thienyl, $\left.R_{2}=C F_{3}\right)$, and FOD $\left(R_{1}=t\right.$-butyl, $\left.R_{2}=n-C_{3} F_{7}\right)$. The properties of these betadiketones are described in the literature ${ }^{10}$. Except TTA, all other beta-diketones tested are liquid at room temperature under atmospheric pressure. In a previous study of the extraction of uranyl ions by supercritical $\mathrm{CO}_{2}$ using FOD as an extractant, it was reported that the presence of a small amount of water would significantly increase the extraction efficiency for the solute from the cellulose based solid material ${ }^{7}$. Water molecules probably form adducts with the uranyl beta-diketone complex and release the complex from the active sites of the cellulose based matrix. Therefore, all solid extraction experiments in this study were conduted under wet conditions by depositing $10 \mu \mathrm{L}$ of water to the system prior to the experiments. 
The results for the extraction of $\mathrm{TH}^{4+}$ and $\left(\mathrm{UO}_{2}\right)^{2+}$ from the cellulose based filter papers are given in Table 1. The experiments were conducted at $60^{\circ} \mathrm{C}$ and $150 \mathrm{~atm}$ with $10 \mu \mathrm{g}$ each of uranium and thorium spiked on Whatman 42 filter paper. As shown in Table 1 , free $\mathrm{Th}^{4+}$ and $\left(\mathrm{UO}_{2}\right)^{2+}$ ions cannot be extracted $(<2 \%)$ by neat $\mathrm{CO}_{2}$ or by methanol $\left(5 \%\right.$ by mole) modified $\mathrm{CO}_{2}$. When the no'n-fluorinated beta-diketone AA was used as the extractant, only $5 \%$ of the spiked uranyl ions can be removed by neat $\mathrm{CO}_{2}$ under the specified conditions. With fluorninated beta-diketone ligands ( $80 \mu$ mole) present in the fluid phase, significant amounts of the spiked uranyl ions can be extracted by supercritical $\mathrm{CO}_{2}$. The percent extraction of the spiked uranyl ions varies from $15 \%$ for TAA to $51 \%$ for FOD. It is apparent from the data that fluorine substitution in beta-diketone can significantly increase the extraction efficiency of the ligand for uranyl ions in supercritical $\mathrm{CO}_{2}$. The percent extraction of $\mathrm{Th}^{4+}$ by supercritical $\mathrm{CO}_{2}$ from the cellulose based matrix varies from $68 \%$ for TAA to $80 \%$ for FOD. The extraction efficiencies of the fluorinated beta-diketones for $\mathrm{TH}^{4+}$ are higher than those found for $\left(\mathrm{UO}_{2}\right)^{2+}$ in supercritical $\mathrm{CO}_{2}$ at $60^{\circ} \mathrm{C}$ and 150 atm. Using the nonfluorinated beta-diketone $\mathrm{AA}$, only $6 \%$ of the spiked $\mathrm{TH}^{4+}$ can be extracted under the same conditions. FOD appears to be the most effective fluorinated beta-diketone for the extraction of $\mathrm{Th}^{4+}$ and $\left(\mathrm{UO}_{2}\right)^{2+}$ in supercritical $\mathrm{CO}_{2}$.

It is known that modifying the polarity of the fluid phase can significantly increase the extraction efficiencies of metal chelates in supercritical $\mathrm{CO}_{2}{ }^{7}$. Using $5 \%$ methanol modified $\mathrm{CO}_{2}$, about 95 98\% of the spiked uranyl ions can be extracted from the wet filter paper when any one of the fluorinated beta-diketone ligands was present in the fluid phase. The extraction efficiencies are very high for all of the four fluorinated beta-diketones such that there is no appreciable difference among them. The non-fluorinated ligand, AA, still shows much lower extraction efficiency relative to the fluorinated beta-diketones in methanol modified $\mathrm{CO}_{2}$. About $45 \%$ of the spiked uranyl ions can be extracted by the methanol modified $\mathrm{CO}_{2}$ under the same conditions. This is also true for the extraction of $\mathrm{Th}^{4+}$ by methanol modified $\mathrm{CO}_{2}$ using beta-diketones as extractants. Acetylacetone can extract $\mathrm{TH}^{4+}$ up to $58 \%$ whereas the fluorinated beta-diketones can extract $\mathrm{Th}^{4+}$ in the $91-97 \%$ range under the same conditions. The rapid and efficient removal of uranyl and thorium ions from the solid material by methanol modified $\mathrm{CO}_{2}$ using this on-line chelation-SFE technique with fluorinated beta-diketones as chelating ligands may have significant application for analysis and treatment of uranium and thorium contaminated materials.

For the extraction of $\mathrm{TH}^{4+}$ and $\left(\mathrm{UO}_{2}\right)^{2+}$ ions from water, TTA was chosen as the extractant because as a solid it is easier than the other beta-diketones to handle experimentally. The ligand was loaded in a cylinder placed upstream from the liquid extraction cell. The $\mathrm{pH}$ of the aqueous solution was controlled at 6.0 using an acetate buffer. The extraction was performed dynamically at 150 atm and $60^{\circ} \mathrm{C}$ for 20 minutes. In the absence of a ligand, free uranyl and thorium ions cannot be extracted $(<2 \%)$ by supercritical $\mathrm{CO}_{2}$ even with $5 \%$ methanol in the fluid phase. With TTA present in $\mathrm{CO}_{2}$, the extraction efficiencies for $\left(\mathrm{UO}_{2}\right)^{2+}$ and $\mathrm{TH}^{4+}$ are $62 \%$ and $75 \%$, respectively, at $60^{\circ} \mathrm{C}$ and $150 \mathrm{~atm}$ after 20 minutes of dynamic extraction. When $5 \%$ methanol modified $\mathrm{CO}_{2}$ was used as the fluid, extraction efficiencies increase to about $82 \%$ and $91 \%$ for $\left(\mathrm{UO}_{2}\right)^{2+}$ and $\mathrm{Th}^{4+}$, respectively, under the same $T, P$, and extraction time. 
Table 1. Percent extraction of $U(V I)$ and Th(IV) from a cellulose based filter paper with supercritical $\mathrm{CO}_{2}$ containing beta-diketones at $150 \mathrm{~atm}$ and $60^{\circ} \mathrm{C}$.

$\begin{array}{lccr}\text { Betă- } & \text { Ligand amount } & \text { Percent Extraction (\%) } \\ \text { diketone } & (\mu \text { mole }) & \text { U(VI) } & \text { Th(IV) }\end{array}$

\begin{tabular}{|c|c|c|c|}
\hline \multicolumn{4}{|c|}{$\mathrm{CO}_{2}$} \\
\hline None & 0 & $<2$ & $<1$ \\
\hline FOD & 80 & $51 \pm 3$ & $80 \pm 3$ \\
\hline TTA & 80 & $30 \pm 2$ & $70 \pm 3$ \\
\hline HFA & 80 & $40 \pm 2$ & $79 \pm 3$ \\
\hline TTA & 80 & $15 \pm 2$ & $68 \pm 3$ \\
\hline AA & 80 & $5 \pm 2$ & $6 \pm 2$ \\
\hline \multicolumn{4}{|c|}{$\mathrm{CO}_{2}+5 \%$ Methanol } \\
\hline FOD & 80 & $98 \pm 3$ & $97 \pm 3$ \\
\hline TTA & 80 & $96 \pm 3$ & $91 \pm 3$ \\
\hline HFA & 80 & $95 \pm 3$ & $92 \pm 4$ \\
\hline TAA & 80 & $98 \pm 3$ & $95 \pm 3$ \\
\hline $\mathrm{AA}$ & 80 & $45 \pm 2$ & $58 \pm 3$ \\
\hline
\end{tabular}

Table 2 shows the results of SFE of uranyl ions from the cellulose based filter paper using TBP as the extractant in supercritical $\mathrm{CO}_{2}$. TBP can extract uranyl ions in supercritical $\mathrm{CO}_{2}$ like TTA and FOD. Since TBP is a neutral ligand, anions such as nitrate or acetate are probably involved in the transport of the uranyl-TBP complex in the fluid phase. These anions are present in the spiked solution since it was prepared with uranyl nitrate in an acetate buffer at $\mathrm{pH}$. The interesting observation is that when TBP is mixed with TTA or FOD, the extraction efficiency for uranyl ions is increased by about a factor of 2 . The extraction efficiency of TBP + TTA for uranyl ions is about $78 \%$ compared ith $40 \%$ and $30 \%$ for individual TBP and TTA, respectively. This is also true for the TBP+FOD mixed ligands; the extraction efficiency for uranyl ions in this case is $78 \%$ compared 
Table 2. Percent extraction of uranyl ions from a cellulose based filter paper containing mixed tributyl phosphate and fluorinated beta-diketones.

\begin{tabular}{lcc}
\hline Ligand & $\begin{array}{c}\text { Amount } \\
(\mu \text { mole })\end{array}$ & $\begin{array}{c}\text { Percent } \\
\text { extraction (\%) }\end{array}$ \\
TBP & 80 & $40 \pm 2$ \\
TBP + TTA & $40+40$ & $78 \pm 3$ \\
TBP + FOD & $40+40$ & $86 \pm 3$ \\
\hline
\end{tabular}

with $40 \%$ and $51 \%$ for the individual ligands. Synergistic extraction, which is used in conventional solvent extraction to improve the efficiency of ligands, apparently can also be used to enhanced the efficiency of actinide extraction in supercritical $\mathrm{CO}_{2}$. Because the extraction efficiency can be greatly enhanced without methanol modifier in this approach, SFE with mixed ligands may avoid the use of any organic solvent. Since a number of neutral ligands are known to form adducts with uranyl-betadiketone complexes, we expect other neutral ligands, besides TBP, may also show positive synergistic extraction effects with the fluorinated beta-diketones. Further studies in SFE of actinides using mixed ligands appears to be an interesting research subject.

This study has demonstrated that thorium and uranyl ions either dissolved in aqueous solution or adsorbed on the cellulose based filter paper can be effectively extracted by methanol modified $\mathrm{CO}_{2}$ containing any one of the fluorinated beta-diketones (TAA, HFA, TTA, and FOD) tested in this study. TBP can also extract uranyl ions in supercritical $\mathrm{CO}_{2}$ to about the same degree as the fluorinated beta-diketones. The extraction efficiency of the mixed ligands (TBP+TTA or TBP +FOD) for uranyl ions was significantly higher than the individual ligands. This new SFE technique offers a host of potential applications for separation of actinides from solid and liquid materials.

\section{ACKNOWLEDGMENT}

This work was supported by a grant from DOE Idaho Field Office under the Office of Technology Development's Innovative Technology Development Program. Neutron irradiations were performed at the Washington State University Nuclear Radiation Center under a Reactor Sharing Program supported by DOE.

\section{REFERENCES}

1. S. B. Hawthorne, Anal. Chem., 62, 1990, 633A.

2. C. A. Eckert, J. G. Van Alsten, and T. Stoicos, Environ. Sci. Technol., 20, 1986, 319. 
3. K. E. Laintz, C. M. Wai, C. R. Yonker, and R. D. Smith, Anal. Chem., 64, 1992, 2875.

4. C. M. Wai, Y. Lin, R. D. Brauer, S. Wang, and W. F. Beckert, Talanta, 1993, in press.

5. K. E. Laintz, J. J. Yu, and C. M. Wai, Anal. Chem., 64, 1992, 311.

6. K. E. Laintz, C. M. Wai, C. R. Yonker, and R. D. Smith, J. Supercrit. Fluids, 4 1991, 194.

7. Y. Lin, R. D. Brauer, K. E. Laintz, and C. M. Wai, Anal. Chem., 1993, in press.

8. J. L. Hedrick, L. J. Mulcahey, and L. T. Taylor, "Supercritical Fluid Technology--Theoretical and Applied Approaches to Analytical Chemistry," ACS Symposium Series 488; Amer. Chem. Soc., Washington, DC, 1991, Bright, F.V. and McNally M.E., eds., p. 206-220.

9. J. Tang, C. M. Wai, Anal. Chem., 58, 1986, 3233.

10. K. L. Cheng, K. Ueno, and T. Imanura, Handbook of Organic Analytical Reagents, CRC Press, Boca Raton, Florida, 1982, p. 85-108. 


\title{
Supercritical Fluid Extraction of Lanthanides with Beta-Diketones and Mixed Ligands
}

\author{
Yuehe Lin, R. D. Brauer, C. M. Wai \\ Department of Chemistry \\ University of Idaho \\ Moscow, Idaho 83843
}

\section{INTRODUCTION}

Supercritical fluid extraction (SFE) has become an attractive alternative to conventional solvent extraction for the recovery of organic compounds from environmental samples. ${ }^{1}$ Carbon dioxide is a gas of choice in SFE because of its moderate critical constants, inertness, and availability in purified form. Although SFE of organic compounds has been the subject of many studies, little information is available in the literature regarding SFE of metals. It is known that direct extraction of metal ions by supercritical $\mathrm{CO}_{2}$ is highly inefficient because of the charge neutralization requirement and the weak solute-solvent interactions. ${ }^{2}$ One approach to solving this problem is by converting the charged metal species into neutral chelates using a suitable chelating agent in the fluid phase. Wai and coworkers have recently demonstrated that $\mathrm{Cu}^{2+}$ and $\mathrm{Hg}^{2+}$ in solid materials can be extracted by supercritical $\mathrm{CO}_{2}$ containing the chelating agent lithium bis(trifluoroethyl)-dithiocarbamate (LiFDDC) ${ }^{2,3}$ The choice of the fluorinated ligand was based on the fact that the solubilities of the metal-FDDC complexes are significantly higher (2-3 orders of magnitude) than the nonfluorinated analogues. ${ }^{4,5}$ The success of this new metal extraction technique for analytical applications depends largely on the effectiveness and availability of the ligand. LiFDDC is an effective ligand for a large number of metal ions but is ineffective for complexation with some elements including the lanthanides. Furthermore, LiFDDC is not available commercially and the starting material for its synthesis is expensive. Recently Wai and coworkers reported that uranyl and trivalent lanthanide ions can be extracted by supercritical $\mathrm{CO}_{2}$ containing a fluorinated beta-diketone, 2,2dimiethyl-6,6,7,7,8,8,8-heptafluoro-3,5-octanedione (FOD). ${ }^{6}$ This observation is significant because a number of fluorinated beta-diketones including FOD are commercially available and are known to form stable complexes with lanthanides and actinides. These fluorinated ligands are potential extractants for SFE of the f-block elements, which may have important applications to nuclear waste analysis and management. The possibility of extracting metal ions using mixed ligands in SFE also has not been reported in the literature. The synergistic extraction of metal ions by mixed ligands may provide another approach to enhance the efficiencies of common ligands for metal recovery in SFE. This paper describes the conditions of extracting lanthanide ions from solid and liquid materials by supercritical $\mathrm{CO}_{2}$ containing different fluorinated beta-diketones and their mixtures with a common ligand tributyl phosphate (TBP). Potential applications of this SFE method for separating the f-block elements from environmental samples are discussed. 


\section{EXPERIMENTAL SECTION}

The iuorinated beta-diketones shown in Table 1 were purchased from the Aldrich Chemical Company (Milwaukee, WI) and used without further purification. Solutions of $\mathrm{La}^{3+}, \mathrm{Eu}^{3+}$, and $\mathrm{Lu}^{3+}$ were prepared from their nitrates, also obtained from Aldrich. All other chemicals used were anaiytical-reagent grade. Filter papers used as the solid sample matrix were obtained from Whatman $\mathrm{L}_{\mathcal{A}}^{\prime} \mathrm{d}$ (Maidstone, England). Solid samples were prepared by spiking $10 \mu \mathrm{g}$ each of a mixture of $\mathrm{La}^{3+}$, $\mathrm{Eu}^{3+}$, and $\mathrm{Lu}^{3+}$ on prewashed filter papers (Whatman $42,0.5 \mathrm{~cm} \times 2 \mathrm{~cm}$ in size, washed with Ultrex $\mathrm{HNO}_{3}$ and rinsed with deionized water). The spiked filter papers were allowed to air dry at a room temperature of $23^{\circ} \mathrm{C}$. Water samples were $0.05 \mathrm{M} \mathrm{HAc/LiAc}$ buffer solution ( $\mathrm{pH}$ 6.5) containing $2.5 \mu \mathrm{g} / \mathrm{mL}$ each of $\mathrm{La}^{3+}, \mathrm{Eu}^{3+}$, and $\mathrm{Lu}^{3+}$.

All experiments were performed with a lab-built SFE apparatus. SFC-grade $\mathrm{CO}_{2}$ or $\mathrm{CO}_{2}$ with 5\% (mole) methanol modifier (Scott Specialty Gases, Plumsteadville, PA) was delivered to the SFE system using a Haskel pump (Haskel Inc., Burbank, CA). The system pressure was monitored to \pm 5 psi using a Setra System (Acton, MA) pressure transducer. The extractor consisted of an inlet valve (SUPELCO, Bellefonte, PA) and an outlet valve connected to an extraction vessel. For the extraction of solid samples, a commercial extraction vessel (Dionex, Sunnyvale, CA) having a volume of $3.5 \mathrm{~mL}$ was used. The main body of the liquid extraction vessel was made from a stainless steel column $(0.75 \mathrm{~cm}$ i.d. and $14 \mathrm{~cm}$ in length, Alltech) and the infittings were obtained from Swagelok (Seattle, WA). The vessel was modified for use with liquid samples in the same manner as reported earlier by Hendrick et al. ${ }^{7}$ The stainless steel inlet and outle: tubes were 0.02 in. internal diameter and extended to within $1 \mathrm{~cm}$ of the top and bottom of the vessel. A $3.5 \mathrm{~mL}$ stainless steel high pressure cylinder containing TTA as chelating agent was connected at upstream of the liquid extraction vessel. The ligand cylinder and the extraction vessel were placed in an oven with

Table 1. Beta-diketones used in this study.

\begin{tabular}{|c|c|c|c|c|c|}
\hline Beta-diketones $^{\mathrm{a}}$ & Abbreviation & $\mathrm{R}_{1}$ & $\mathrm{R}_{2}$ & $\begin{array}{l}\text { Molecular } \\
\text { weight }\end{array}$ & $\begin{array}{l}\text { B.P. } \\
\left({ }^{\circ} \mathrm{C}\right)\end{array}$ \\
\hline Acetylacetone & $\mathrm{AA}$ & $\mathrm{CH}_{3}$ & $\mathrm{CH}_{3}$ & 100.12 & $\begin{array}{l}139^{\circ} \\
(760 \text { Torr })\end{array}$ \\
\hline Trifluoroacetylacetone & TAA & $\mathrm{CH}_{3}$ & $\mathrm{CF}_{3}$ & 154.09 & $107^{\circ}$ \\
\hline Hexafluoroacetylacetone & HFA & $\mathrm{CF}_{3}$ & $\mathrm{CF}_{3}$ & 208.06 & $70-71^{\circ}$ \\
\hline Thenoyltrifluoroacetone & TTA & $\pi{ }_{3}^{\|}$ & $\mathrm{CF}_{3}$ & 222.18 & $\begin{array}{l}103-104^{\circ} \\
(9 \text { Torr) }\end{array}$ \\
\hline $\begin{array}{l}\text { Heptafluorobutanoylpivaroyl- } \\
\text { methane }\end{array}$ & FOD & $\mathrm{C}\left(\mathrm{CH}_{3}\right)_{3}$ & $\mathrm{C}_{3} \mathrm{~F}_{7}$ & 296.18 & $\begin{array}{l}33^{\circ} \\
(2.7 \text { Torr })\end{array}$ \\
\hline a. $\quad R_{1}-\frac{C}{\delta}-C H_{2}-\stackrel{C}{\delta}-R_{2}$ & & & & & \\
\hline
\end{tabular}


temperature controlled to $\pm 0.1^{\circ} \mathrm{C}$ by an OMEGA (Stamford, CT) CN9000A temperature controller. A fused-silica tubing (Dionex, $50 \mu \mathrm{m}$ i.d. and $20 \mathrm{~cm}$ in length) was used as the pressure restrictor for the exit gas. The SFE system allows static and dynamic extraction steps to be carried out by closing and opening of the inlet and outlet valves.

For solid sample extraction, a glass tube $(0.5 \mathrm{~cm}$ i.d. and $3 \mathrm{~cm}$ in length) was plugged at one end with a piece of glass wool, previously cleaned with Ultrex nitric acid. To the open end of the glass tube, a spiked filter sample was inserted. About $80 \mu$ moles of a beta-diketone ligand was introduced to the sample and the open end was plugged with a piece of clean glass wool. The sample tube was placed immediately into the extraction vessel and installed in the SFE oven. The temperature of the oven was set at $60^{\circ} \mathrm{C}$ and the cell was pressurized to $150 \mathrm{~atm}$. The chelation and the extraction processes were allowed to occur under a static SFE condition for 10 minutes. After that, the exit valve was opened and the sample was extracted and flushed under dynamic condition for 10 minutes. The specified extraction conditions were adopted based on a previous study regarding the SFE of lanthanides using FOD as an extractant. ${ }^{6}$ When the dynamic extraction step was completed, the sample was removed from the SFE system and the filter paper was analyzed by a nondestructive neutron activation analysis (NAA). A standard filter paper containing the same amount of the lanthanide and actinide ions was irradiated and counted with the sample under identical conditions. The extraction efficiencies were calculated based on the amount of the lanthanide found in the filter paper before and after the extraction.

For the extraction of the lanthanides from water, $4 \mathrm{~mL}$ of the spiked water sample were placed in the liquid extraction vessel. The $\mathrm{pH}$ of the solution was controlled by an acetate buffer. The water samples usually contained $2.5 \mu \mathrm{g} / \mathrm{mL}$ each of $\mathrm{La}^{3+}, \mathrm{Eu}^{3+}$, and $\mathrm{Lu}^{3+}$. A certain amount of TTA (approximately $50 \mathrm{mg}$ ) was loaded in the ligand cylinder placed upstream from the liquid extraction vessel. The samples were extracted dynamically at $60^{\circ} \mathrm{C}$ and $150 \mathrm{~atm}$ for 20 minutes. When the extraction was completed, the sample was removed from the extraction vessel and analyzed by NAAA. Standard solution containing $2.5 \mu \mathrm{g} / \mathrm{mL}$ each of the lanthanide ions was irradiated and counted with the sample under identical conditions. The extraction efficiencies were calculated based on the amounts of the lanthanides found in the aqueous solution before and after the extraction. The solutes trapped in the chloroform solution were determined by back-extraction with $50 \% \mathrm{HNO}_{3}$ followed by NAA of the acid solution. The results were also used for recovery calculations.

All samples and standards were irradiated for $2 \mathrm{~h}$ in a $1 \mathrm{MW}$ TRIGAR nuclear reactor at a steady flux of $6 \times 10^{12} \mathrm{n} \mathrm{cm}^{-2} \mathrm{~s}^{-1}$. After irradiation, the samples were cooled for $24 \mathrm{~h}$ before counting. Each sample was counted for $100 \mathrm{~s}$ in a large-volume ORTEC Ge(Li) detector with a resolution (FWHM) of about $2.3 \mathrm{keV}$ at the $1332-\mathrm{keV}{ }^{60} \mathrm{Co}$ peak. The following radioisotopes and their characteristic gamma energies were used for identification and quantification of the lanthanides: ${ }^{140} \mathrm{La}(40.2 \mathrm{~h}, 487 \mathrm{keV}),{ }^{152 \mathrm{~m}} \mathrm{Eu}(9.3 \mathrm{~h}, 121 \mathrm{keV})$, and ${ }^{177} \mathrm{Lu}(6.7 \mathrm{~d}, 208 \mathrm{keV})$. The detailed procedures of NAA are described elsewhere. ${ }^{8}$ 


\section{RESULTS AND DISCUSSION}

\section{SFE of Lanthanides from Solid Material with Beta-Diketones}

The beta-diketones and their abbreviations used in this study are given in Table 1. Except thenolytrifluoroacetone (TTA), other beta-diketones listed the table are all liquid at room temperature under atmospheric pressure. In our previous SFE study of lanthanides using FOD as an extractant, we noted that the presence of a small amount of water would significantly enhance the extraction efficiency of lanthanides from the cellulose based solid material. ${ }^{6}$ Water molecules probably compete with the active sites of the cellulose matrix to release the lanthanide-FOD complexes as water adducts. The lanthanide-FOD complexes are known to form adducts with water and other Lewis bases, a property which makes them useful as lanthanide shifting agents. ${ }^{9}$ Therefore, the solid samples in this SFE study were all extracted under wet conditions by depositing $10 \mu \mathrm{L}$ of water to the filter paper immediately before the experiment.

The results of extracting $\mathrm{La}^{3+}, \mathrm{Eu}^{3+}$, and $\mathrm{Lu}^{3+}$ from the cellulose based filter paper by supercritical $\mathrm{CO}_{2}$ containing different beta-diketones are given in Table 2 . It is known that without a chelating agent, the spiked lanthanides cannot be extracted from the filter paper by supercritical $\mathrm{CO}_{2}{ }^{6}$ In the presence of a beta-diketone, the spiked lanthanides become extractable by $\mathrm{CO}_{2}$ under the specified experimental conditions (10 minutes of static extraction followed by 10 minutes of dynamic flushing at $60^{\circ} \mathrm{C}$ and $150 \mathrm{~atm}$ ). The extraction efficiency for the lanthanides was found to depend on the structure of the ligand following approximately the order TTA $\approx F O D>H F A>$ TAA $>$ AA. Acetylacetone (AA) which has the lowest molecular weight and with no fluorine substitution is the least effective ligand for the SFE of lanthanides. The efficiencies for the extraction of $\mathrm{La}^{3+}, \mathrm{Eu}^{3+}$, and $\mathrm{Lu}^{3+}$ from the solid material are $6 \%$ or less when $\mathrm{AA}$ was used as an extractant in supercritical $\mathrm{CO}_{2}$ under the specified conditions. Substitution of $\mathrm{CF}_{3}$ for the methyl groups in $\mathrm{AA}$ increases the efficiency of lanthanide extraction as indicated by TAA and HFA. Hexafluoroacetylacetone (HFA) is able to extract the lanthanides from the filter paper up to $17 \%$. Thenoyltrifluoroacetylacetone (TTA), having a bulky thienyl substitution for the methyl group, is slightly more effective than HFA for the extraction of the lanthanides from the solid material with neat $\mathrm{CO}_{2}$. The extraction efficiencies for $\mathrm{La}^{3+}, \mathrm{Eu}^{3+}$, and $\mathrm{Lu}^{3+}$ are $14 \%, 17 \%$, and $20 \%$, respectively, at $60^{\circ} \mathrm{C}$ and $150 \mathrm{~atm}$. The extraction efficiency of FOD for the lanthanides is similar to that of TTA. All of the fluorinated beta-diketones tested show a preference for the heavy lanthanides over the light one under our SFE conditions. Overall speaking, the extraction efficiency for the trivalent lanthanides by neat $\mathrm{CO}_{2}$ is not very high, with the highest percentage of extraction occurring with TTA, which extracts $\mathrm{Lu}^{3+}$ at $20 \%$ under our experimental conditions.

The addition of methanol to $\mathrm{CO}_{2}$ modifies the polarity of the fluid phase which has been shown to result in an enhanced extraction of metal chelates in supercritical $\mathrm{CO}_{2}{ }^{3,6}$ The extraction efficiencies for $\mathrm{La}^{3+}, \mathrm{Eu}^{3+}$, and $\mathrm{Lu}^{3+}$ with $\mathrm{FOD}$ as an extractant were significantly improved (>90\%) when $5 \%$ of methanol were present in the fluid phase. ${ }^{6}$ This appears to be generally true for other fluorinated beta-diketones investigated in this work. For example, in the case of TTA, the extraction efficiencies for $\mathrm{La}^{3+}, \mathrm{Eu}^{3+}$, and $\mathrm{Lu}^{3+}$ become $74 \%, 90 \%$, and $94 \%$, respectively, in methanol modified $\mathrm{CO}_{2}$ under the specified experimental conditions given in Table 2. Similar enhancement 
Table 2. Percent extraction of $\mathrm{La}^{3+}, \mathrm{Eu}^{3+}$, and $\mathrm{Lu}^{3+}$ from a cellulose based filter paper with supercritical $\mathrm{CO}_{2}$ containing beta-diketones at $150 \mathrm{~atm}$ and $60^{\circ} \mathrm{C}$.

Percent extraction

$(\%)$

\begin{tabular}{|c|c|c|c|c|}
\hline Beta-diketone & $\begin{array}{l}\text { Ligand } \\
\text { amount } \\
\text { ( } \mu \text { mole) }\end{array}$ & $\mathrm{La}^{3+}$ & $\mathrm{Eu}^{3+}$ & $\mathrm{Lu}^{3+}$ \\
\hline \multicolumn{5}{|c|}{$\mathrm{CO}_{2}$} \\
\hline FOD & 80 & $10 \pm 1$ & $13 \pm 1$ & $19 \pm 1$ \\
\hline TTA & 80 & $14 \pm 2$ & $17 \pm 3$ & $20 \pm 3$ \\
\hline HFA & 80 & $6 \pm 2$ & $16 \pm 2$ & $17 \pm 2$ \\
\hline TAA & 80 & $5 \pm 2$ & $14 \pm 2$ & $15 \pm 2$ \\
\hline $\mathbf{A A}$ & 80 & $5 \pm 2$ & $4 \pm 2$ & $6 \pm 2$ \\
\hline \multicolumn{5}{|c|}{$\mathrm{CO}_{2}+5 \% \mathrm{MeOH}$} \\
\hline FOD & 80 & $91 \pm 2$ & $96 \pm 2$ & $99 \pm 1$ \\
\hline TTA & 80 & $74 \pm 3$ & $90 \pm 2$ & $94 \pm 3$ \\
\hline HFA & 80 & $70 \pm 3$ & $93 \pm 4$ & $95 \pm 3$ \\
\hline TAA & 80 & $54 \pm 2$ & $84 \pm 3$ & $88 \pm 3$ \\
\hline AA & 80 & $11 \pm 2$ & $25 \pm 2$ & $33 \pm 3$ \\
\hline
\end{tabular}

in extraction efficiencies for the lanthanides was also observed for HFA in methanol modified $\mathrm{CO}_{2}$. TAA with only one $\mathrm{CF}_{3}$ substitution for the methyl groups in acetylacetone, shows a slightly lower enhancement in extraction efficiencies for the lanthanides relative to HFA. The extraction efficiencies for $\mathrm{La}^{3+}, \mathrm{Eu}^{3+}$, and $\mathrm{Lu}^{3+}$ by methanol modified $\mathrm{CO}_{2}$ containing dissolved TAA are 54\%, $88 \%$, and $84 \%$, respectively. Without fluorine substitution in beta-diketone, the ligand does not seem to be effective for lanthanide extraction even with methanol modified $\mathrm{CO}_{2}$. The percent of extraction of $\mathrm{La}^{3+}, \mathrm{Eu}^{3+}$, and $\mathrm{Lu}^{3+}$ with $\mathrm{AA}$ in methanol modified $\mathrm{CO}_{2}$ under the same experimental conditions are only $11 \%, 25 \%$, and $33 \%$, respectively.

The lanthanide-beta-diketone complexes are usually solids with limited volatility. For instance the melting points of $\mathrm{La}^{3+}$ complexes with TAA, HFA, TTA, and FOD were reported to be $169^{\circ} \mathrm{C}$, $120-125^{\circ} \mathrm{C}, 135^{\circ} \mathrm{C}$, and $215-230^{\circ} \mathrm{C}$, respectively. ${ }^{10,11}$ The solubility of $\mathrm{La}(\mathrm{FOD})_{3}$ in supercritical $\mathrm{CO}_{2}$ $\left(5.5 \times 10^{-2} \mathrm{M}\right.$ at $60^{\circ} \mathrm{C}$ and $\left.150 \mathrm{~atm}\right)$ is considered high for metal chelates. The solubilities of other lanthanum-fluorinated beta-diketones in supercritical $\mathrm{CO}_{2}$ are also expected to be high. The total amount of each lanthanide present in the solid material, even if it is all extracted in the fluid phase, is about three orders of magnitude lower than the solubility limit of their beta-diketone complexes. The extraction efficiencies for the lanthanides observed from the solid experiments are obviously not determined by solubility alone. Water molecules help to release the lanthanide-beta-diketone complexes from the matrix by forming adducts with the lanthanide complexes. It can be considered as a matrix modifier in this case. Methanol modified $\mathrm{CO}_{2}$ probably further enhances the solubility and mobility of the adducts in the fluid phase, leading to much higher extraction efficiency for the lanthanides. 


\section{Synergistic Extraction of Lanthanides in SFE}

In addition to the beta-diketones, a neutral ligand TBP was also tested for lanthanide extraction in our SFE experiments. TBP shows limited extraction of the lanthanides $(<11 \%)$ from the solid material as shown in Table 3. Since TBP is neutral, the lanthanide complexes are probably extracted with other anions such as nitrate or acetate present in the sample. The spike solution was prepared using the nitrate salts of the lanthanides in an acetate buffer. These anions are expected to be present in the lanthanide spiked solid samples. When TBP is mixed with either TTA or FOD, the extraction efficiency of the mixed ligands for the lanthanides is dramatically improved with respect to each individual ligand. The percent extraction of $\mathrm{La}^{3+}$ with a mixture of TBP and TTA by supercritical $\mathrm{CO}_{2}$ at 150 atm and $60^{\circ} \mathrm{C}$ increases to $90 \%$ comparing with $8 \%$ and $14 \%$ for individual TBP and TTA, respectively. Under the same conditions, $\mathrm{Lu}^{3+}$ was extracted up to $93 \%$ relative to $11 \%$ and $20 \%$ for TBP and TTA, respectively. The mixed TTA-TBP ligands still show a preference of extracting the heavy lanthanides over the light ones, but the difference is not as large as those observed from each individual ligand. Similar degrees of synergistic extractions of the lanthanide ions were also observed when a mixture of TBP and FOD was used in the SFE experiments. For example, the extraction efficiencies for $\mathrm{La}^{3+}, \mathrm{Eu}^{3+}$, and $\mathrm{Lu}^{3+}$ by a mixture of TBP and FOD are $80 \%, 93 \%$, and $95 \%$, respectively.

Synergistic extractions of lanthanides by mixed ligands were observed in solvent extraction experiments. ${ }^{12}$ The coordination number of trivalent lanthanide $\left(\mathrm{Ln}^{3+}\right)$ ions is usually large, up to 9 or 10 . TBP probably competes with the cellulose matrix for the unoccupied coordination sites by forming adducts with the $\mathrm{Ln}$ (TTA) ${ }_{3}$ complexes in supercritical $\mathrm{CO}_{2}$, making them easier to move from the solid phase into the fluid phase. The high efficiency of lanthanide extraction observed from the mixed TBP and beta-diketone ligands in supercritical $\mathrm{CO}_{2}$ appears significant for analytical applications as well as for waste management. In this approach, methanol is unnecessary for the extraction, thus no organic solvent would be involved in the extraction process. The enhanced extraction observed from the mixed ligands also implies that other neutral ligands may also be used for synergistic extraction of lanthanides with the fluorinated beta-diketones.

Table 3. Percent extraction of $\mathrm{La}^{3+}, \mathrm{Eu}^{3+}$, and $\mathrm{Lu}^{3+}$ from the filter paper with neat $\mathrm{CO}_{2}$ containing mixed ligands at $150 \mathrm{~atm}$ and $60^{\circ} \mathrm{C}$.

Percent extraction

$(\%)$

\begin{tabular}{lcccc}
\cline { 4 - 4 } \multicolumn{1}{c}{ Ligands } & $\begin{array}{c}\text { Amount } \\
(\mu \text { mole })\end{array}$ & $\mathrm{La}^{3+}$ & $\mathrm{Eu}^{3+}$ & $\mathrm{Lu}^{3+}$ \\
\hline TBP & 80 & $2 \pm 1$ & $3 \pm 1$ & $4 \pm 1$ \\
TBP + TTA & $40+40$ & $90 \pm 2$ & $92 \pm 2$ & $93 \pm 2$ \\
TBP + FOD & $40+40$ & $80 \pm 2$ & $93 \pm 2$ & $95 \pm 3$ \\
\hline
\end{tabular}




\section{SFE of Lanthanides from Aqueous Solution}

TTA was chosen as the chelating agent for the liquid extraction experiments because it is a solid which is easier to handle experimentally than the other liquid beta-diketones. The ligand in excess amount was put in a cylinder placed upstream from the liquid extractor. The $\mathrm{pH}$ of the solution was controlled at 6.0 using an acetate buffer. According to the literature, at this $\mathrm{pH}$ the lanthanides can be extracted by TTA in conventional solvent extraction experiments. ${ }^{12}$ The SFE experiments for the liquid samples were performed dynamically at $150 \mathrm{~atm}$ and $60^{\circ} \mathrm{C}$ for 20 minutes and the results are given in Table 4. Without the ligand, the lanthanide ions in solution cannot be extracted $(<2 \%)$ by supercritical $\mathrm{CO}_{2}$ even with $5 \%$ methanol in the fluid phase. With TTA present in the fluid phase, about $41-61 \%$ of the lanthanides can be extracted under the specified experiment conditions. When $5 \%$ methanol modified $\mathrm{CO}_{2}$ was used as the fluid, the extraction efficiencies for $\mathrm{La}^{3+}, \mathrm{Eu}^{3+}$, and $\mathrm{Lu}^{3+}$ were increased to $70 \%, 78 \%$, and $81 \%$, respectively. The extracted lanthanides were also trapped in chloroform for NAA. The amounts of $\mathrm{La}, \mathrm{Eu}$, and $\mathrm{Lu}$ recovered from the trap solution were determined to be $68 \%, 75 \%$, and $80 \%$, respectively, in good agreement with the percent extraction evaluated from the sample solution.

\section{CONCLUSION}

This study has demonstrated that fluorinated beta-diketones HFA, TTA, and FOD are effective extractants for the trivalent lanthanide ions in supercritical $\mathrm{CO}_{2}$. High extraction efficiencies for the trivalent lanthanide ions spiked on the cellulose based matrix can be achieved with water molecules as a matrix modifier and methanol as a solvent modifier. Synergistic extraction of the lanthanide ions with TBP and the beta-diketones was also observed. Using a mixture of TBP and TTA or FOD, high extraction efficiencies for the lanthanides were observed with neat $\mathrm{CO}_{2}$. Rapid extraction of lanthanides from aqueous solutions can also be achieved with methanol modified $\mathrm{CO}_{2}$ containing TTA. This online chelation-supercritical fluid extraction approach offers a host of potential applications for separation of lanthanides from environmental samples and waste materials.

Table 4. Percent extraction of $\mathrm{La}^{3+}, \mathrm{Eu}^{3+}$, and $\mathrm{Lu}^{3+}$ from aqueous solution with supercritical $\mathrm{CO}_{2}$ containing TTA at 150 atm and $60^{\circ} \mathrm{C}$.

\begin{tabular}{|c|c|c|c|c|}
\hline \multirow[b]{2}{*}{ Ligand } & \multirow[b]{2}{*}{ Fluid phase } & \multicolumn{3}{|c|}{$\begin{array}{c}\text { Percent extraction } \\
(\%)\end{array}$} \\
\hline & & $\mathrm{La}^{3+}$ & $\mathrm{Eu}^{3+}$ & $\mathrm{Lu}^{3+}$ \\
\hline None & $\mathrm{CO}_{2}$ & $<2$ & $<2$ & $<2$ \\
\hline None & $\mathrm{CO}_{2}+5 \% \mathrm{MeOH}$ & $<2$ & $<2$ & $<2$ \\
\hline TTA & $\mathrm{CO}_{2}$ & $41 \pm 3$ & $61 \pm 4$ & $61 \pm 4$ \\
\hline TTA & $\mathrm{CO}_{2}+5 \% \mathrm{MeOH}$ & $70 \pm 3$ & $78 \pm 4$ & $81 \pm 3$ \\
\hline
\end{tabular}




\section{ACKNOWLEDGMENTS}

This work was supported by a grant from DOE Idaho Field Office under the Office of Technology Development's Innovative Technology Development Program. Neutron irradiations were performed at the Washington State University Nuclear Radiation Center under a Reactor Sharing Program supported by DOE.

\section{REFERENCES}

1. S. B. Hawthorne, Anal. Chem., $62,1990,633 \mathrm{~A}$.

2. K. E. Laintz, C. M. Wai, C. R. Yonker, and R. D. Smith, Anal. Chem. 64, 1992, 2875.

3. C. M. Wai, Y. Lin, R. D. Brauer, S. Wang, and W. F. Beckert, Talanta, 1993, in press.

4. K. E. Laintz, C. M. Wai, C. R. Yonker, and R. D. Smith, J. Supercrit. Fluids 4, 1991, 194.

5. K. E. Laintz, J. J. Yu, and C. M. Wai, Anal. Chem., 62, 1992, 311.

6. Y. Lin, R. D. Brauer, K. E. Laintz, and C. M. Wai, Anal. Chem., 1993, in press.

7. J. L. Hedrick, L. J. Mulcahey, and L. T. Taylor, "Supercritical Fluid Technology-Theoretical and Applied Approaches to Analytical Chemistry," ACS Symposium Series 488; Amer. Chem. Soc., Washington, DC, 1991, F. V. Bright and M. D. McNally, eds., pp. 206-220.

8. J. Tang and C. M. Wai, Anal. Chem., 58, 1986, 3233.

9. S. Cotton, Lanthanides and Actinides, Oxford University Press, N.Y., 1991, p. 59.

10. C. S. Springer, D. W. Meek, and R. E. Sievers, Inorg. Chem. 6, 1967, p. 1105.

11. D. Purushotham, V. R. Rao, and S.V.R. Rao, Anal. Chem. Acta, 33, 1965, p. 182.

12. E. C. Cox and M. W. Davis, Sep. Sci. Technol. 8, 1973, p. 205. 


\title{
A Group Contribution Method for Predicting the Solubilities of Solid Organic Compounds in Supercritical Carbon Dioxide
}

\author{
J. D. Harrington, Hao Jiang, T. E. Carleson, and C. M. Wal \\ Department of Chemistry and Department of Chemical Engineering, \\ University of Idaho \\ Moscow, Idaho, 83843
}

\begin{abstract}
The Peng-Robinson equation of state and thermodynamic equilibrium are used to predict the solubilities of organic solids in supercritical $\mathrm{CO}_{2}$ from the sublimation pressure, critical properties, and acentric factor of the solutes of interest. Classical Van der Waals mixing rules with an interaction parameter $k_{\mathrm{ij}}$ are employed. A group contribution method for estimating $k_{\mathrm{ij}}$ is developed and evaluated. It is found that this method can predict $k_{\mathrm{ij}}$ within $17 \%$ for the aromatic compounds considered in this paper.

\section{INTRODUCTION}

Supercritical fluids are useful solvents having properties in between those of gases and liquids. Their densities approach those of liquids, and solid solubilities are usually much higher in supercritical fluids than they are in gases. Their diffusivities and viscosities approach those of gases. In a supercritical fluid, the solubility of a solid can change orders of magnitude with moderate changes of pressure and temperature. Because of this flexibility, and their other desirable properties, supercritical solvents have become increasingly important in extraction processes. Of all of the supercritical fluids, supercritical $\mathrm{CO}_{2}$ is the most useful. It is cheap and nontoxic, and it has a convenient critical point at 72.8 bar and $31^{\circ} \mathrm{C} .^{1-4}$.

This paper focuses on predicting the solubilities or organic compounds in supercritical $\mathrm{CO}_{2}$, using the solute's chemical structure and certain physical properties (sublimation pressure, solid density, the critical constants, and the acentric factor). In the past, investigators have employed equations of state to calculate supercritical solubility. ${ }^{5}$ Often, however, necessary constants are not available for solubility prediction; the Peng-Robinson equation, for example, has mixing rules that require an interaction parameter between the solute and the supercritical solvent, denoted as $k_{\mathrm{ij}}$, and presently there is no method for calculating $k_{\mathrm{ij}}$ theoretically. This research evaluates the effectiveness and accuracy of a group contribution method for predicting $k_{\mathrm{ij}}$, and the quality supercritical solubilities calculated using predicted values of $k_{\mathrm{ij}}$.
\end{abstract}




\section{THEORY AND EQUATIONS}

From thermodynamics, the following equation can be derived, which expresses the solubility of a solid solute in a supercritical fluid as a function of pressure and temperature:

$y_{i}=\frac{\rho_{i}^{0} \phi_{i}^{0}}{P \phi_{I}} \exp \left(\int_{p_{i}^{0}}^{P} \frac{v_{i}^{8}}{R T} d P\right)$,

where $y_{i}$ is the mole fraction of the solute in the supercritical phase, $p_{i}^{0}$ is the vapor pressure of the pure solute at temperature $T, \phi_{i}^{0}$ is the fugacity coefficient of the pure, saturated solute vapor, $v_{i}^{*}$ is the molar volume of the solid solute, $\phi_{\mathrm{i}}$ is th: fugacity coefficient of the solute vapor in the supercritical solvent, $P$ and $T$ are the system pressure and temperature, and $R$ is the ideal gas constant. If the solid is relatively incompressible and nonvolatile, then $\phi_{i}^{0}$ is one and $v_{i}^{s}$ is independent of pressure. In this case the equation reduces to

$y_{i}=\frac{\rho_{i}^{0}}{P \phi_{i}} \exp \left(\frac{v_{i}^{s}\left(P-\rho_{i}^{0}\right)}{R T}\right)$.

From thermodynamics, it can be shown that

$R T \ln \phi_{i}=-\int_{-}^{\nu}\left[\left(\frac{\partial P}{\partial n_{i}}\right)_{T, V, n_{j}}-\frac{R T}{V}\right] d V-R T \ln Z$,

when $n_{i}$ is the number of moles of component $i$ in the supercritical mixture, and $Z$ is the mixture's compressibility.

Use equation 3 , the fugacity coefficient of a solute, $\phi_{i}$, can be determined from an equation of state. This research employs the Peng-Robinson equation,

$P=\frac{R T}{V-b}-\frac{a}{V(V+b)+v(V-b)}$

For a pure substance, the parameters $a$ and $b$ are caluclated from the critical properties and Pitzer's acentric factor. ${ }^{6}$ For a mixture, the parameters $a$ and $b$ (denoted as $a_{\mathrm{m}}$ and $b_{\mathrm{m}}$ ) are found from classical mixing rules with an interaction parameter: 


$$
\begin{aligned}
& a_{m}=\sum_{i=1}^{n} \sum_{j=1}^{n} y_{i} y_{j} a_{j}, \\
& b_{m}=\sum_{i=1}^{n} \sum_{j=1}^{n} y_{i} y_{j} b_{j},
\end{aligned}
$$

where $a_{\mathrm{ij}}$ and $b_{\mathrm{ij}}$ are given by the equations

$$
\begin{aligned}
& a_{i}=\left(1-k_{i j}\right)\left(a_{i} a_{j}\right)^{k}, i \neq j, \\
& a_{i j}=a_{i}, \\
& b_{i}=\frac{1}{2}\left(b_{i}+b_{j}\right),
\end{aligned}
$$

where $n$ is the number of components in the mixture, $y_{i}$ is the mole fraction of the $i$ th component, $a_{\mathrm{i}}$ and $b_{\mathrm{i}}$ are the parameters for the pure $i$ th component, and $k_{\mathrm{ij}}$ is the interaction parameter between component $i$ and component $j$. It is assumed that $k_{\mathrm{ij}}$ is independent of temperature and pressure.

Using the Peng-Robinson equation, it follows that

$$
1 n \phi_{i}=\frac{b_{i}}{b_{m}}(Z-1)-\ln (Z-B)+\frac{A}{2^{\frac{3}{2}} B}\left(\frac{2 \sum_{j+1}^{n} y a_{i}}{a_{m}}-\frac{b_{i}}{b_{m}}\right) \ln \left(\frac{Z-B\left(1-2^{\frac{1}{2}}\right)}{Z+B\left(1+2^{\frac{1}{2}}\right)}\right),
$$

where $A=a_{\mathrm{m}} P / R T^{2}$ and $B=b_{\mathrm{m}} P / R T$.

\section{ESTIMATION OF $K_{I J}$ BY GROUP CONTRIBUTION}

When the solubility of an organic compound in supercritical $\mathrm{CO}_{2}$ is known at various temperatures and pressure, $k_{\mathrm{ij}}$ can be calculated by adjusting it to minimize the objective function

$F=\frac{1}{N}\left[\sum_{i=1}^{n}\left(\frac{y_{\text {cal. }}-y_{\text {exp. }}}{y_{\text {exp. }}}\right)^{2}\right]^{\frac{1}{2}}$,

which is a measure of the average deviation between the $N$ values of $y_{\text {exp. }}$ and the $N$ values of $y_{\text {cal. }}$ at corresponding temperatures and pressures. In this research, each $k_{\mathrm{ij}}$ value was calculated from points on a single solubility isotherm. The physical data for the calculation is recorded in Table 1. 
Table 1. Data sources for calculation of $k_{\mathrm{ij}}$.

\begin{tabular}{|c|c|c|c|c|c|c|}
\hline Compound & $\begin{array}{c}\mathrm{CO}_{2} \\
\text { solubility }\end{array}$ & $\begin{array}{c}\text { Sublimation } \\
\text { pressure }\end{array}$ & $\mathrm{Tc}(\mathbf{K})$ & Pc(atm) & Omega & $\begin{array}{c}\text { Reference } \\
\text { for Tc, Pc, } \\
\text { \& omega }\end{array}$ \\
\hline $\mathrm{CO}_{2}$ & - & - & 304.2 & 72.8 & 0.239 & Ref. 20 \\
\hline Benzoic Acid & Ref. 7 & Refs. $17 \& 18$ & 752 & 45 & 0.62 & Ref. 20 \\
\hline Fluorene & Ref. 8 & Refs. $17 \& 18$ & 821 & 29.7 & 0.451 & Ref. 21 \\
\hline Naphthalene & Ref. 9 & Refs. $17 \& 18$ & 747.8 & 40.5 & 0.303 & Ref. 20 \\
\hline 2,3-Dimethylnaphthalene & Ref. 10 & Ref. 17 & 777.8 & 29.8 & 0.443 & Ref. 20 \\
\hline 2,6-Dimethylnaphthalene & Ref. 10 & Ref. 17 & 769.2 & 30.1 & 0.443 & Ref. 20 \\
\hline Phenanthrene & Ref. 8 & Refs. $17 \& 18$ & 890 & 32.5 & 0.429 & Ref. 21 \\
\hline Phenol & Ref. 11 & Refs. $17 \& 18$ & 694.3 & 60.5 & 0.44 & Ref. 20 \\
\hline Pyrene & Ref. 8 & Refs. $17 \& 18$ & 936 & 25.7 & 0.498 & Ref. 21 \\
\hline Anthracene & Ref. 9 & Refs. $17 \& 18$ & 874.5 & 28.6 & 0.464 & * \\
\hline Biphenyl & Ref. 12 & Refs. $17 \& 18$ & 789 & 38 & 0.372 & Ref. 20 \\
\hline 2-Naphthol & Ref. 7 & Refs. $17 \& 18$ & 820.9 & 41.7 & 0.561 & * \\
\hline 1,4-Naphthoquinone & Ref. 7 & Ref. 19 & 792 & 40.7 & 0.575 & * \\
\hline Triphenylmethane & Ref. 13 & Ref. 17 & 863 & 22.1 & 0.576 & * \\
\hline Hexamethylbenzene & Ref. 13 & Ref. 17 & 758 & 22.1 & 0.396 & Ref. 20 \\
\hline 2,5-Xylenol & Ref. 14 & Ref. 17 & 707 & 41.5 & 0.546 & Ref. 20 \\
\hline o-Hydroxybenzoic Acid & Ref. 15 & Ref. 17 & 672.7 & 51 & 0.563 & * \\
\hline
\end{tabular}

For each compound, the $k_{\mathrm{ij}}$ values obtained for the various temperatures were average. The mean and standard deviation of $k_{\mathrm{ij}}$ is given in Table 2 for each of the 16 compounds studied.

To predict $k_{\mathrm{ij}}$ for an applicable organic compound whose solubility in $\mathrm{CO}_{2}$ has never been determined, a simple group contribution equation is employed of the form

$k_{i j}=c+\sum n_{k} \Delta_{k}$

where the sum extends over all of the groups in the solute molecule, $\Delta_{k}$ is a group increment corresponding to a specific group in the solute molecule, $n_{k}$ is the number of times that the group appears in the solute molecule, and $c$ is the regression intercept. The values of $\Delta_{k}$ for various chemical groups in our group contribution method were determined using multiple regression, fitting 
Table 2. Calculated $k_{\mathrm{ij}}$ values based on the solubility data given in Table 1 .

\begin{tabular}{lcccc}
\multicolumn{1}{c}{ Name } & $\begin{array}{c}\text { Average } \\
k_{\mathrm{ij}}\end{array}$ & $\begin{array}{c}\text { Standard } \\
\text { deviation } \\
\text { of } k_{\mathrm{ij}}\end{array}$ & $\begin{array}{c}\text { Regular } \\
k_{\mathrm{ij}}\end{array}$ & $\begin{array}{c}\text { Percent } \\
\text { deviation }\end{array}$ \\
\hline & & & & \\
Benzoic acid & 0.036 & 0.002 & 0.042 & 16.8 \\
Fluorene & 0.104 & 0.002 & 0.104 & 0.0 \\
Napthalene & 0.099 & 0.003 & 0.094 & -5.6 \\
2,3-Dimethylnaphthalene & 0.100 & 0.002 & 0.090 & -9.1 \\
2,6-Dimethylnaphthalene & 0.094 & 0.002 & 0.090 & -4.1 \\
Phenanthrene & 0.116 & 0.005 & 0.102 & -12.3 \\
Phenol & 0.099 & - & 0.102 & 3.1 \\
Pyrene & 0.095 & 0.005 & 0.105 & 10.8 \\
Anthracene & 0.099 & 0.004 & 0.102 & 2.6 \\
Biphenyl & 0.087 & 0.001 & 0.098 & 11.8 \\
2-Naphthol & 0.109 & 0.011 & 0.110 & 0.6 \\
2,5-Xylenol & 0.096 & - & 0.099 & 2.5 \\
0-Hydroxybenzoic acid & 0.065 & 0.012 & 0.058 & -9.5 \\
1,4-Naphthoquinone & 0.051 & 0.002 & 0.051 & 0.0 \\
Triphenylmethane & 0.096 & 0.004 & 0.096 & 0.0 \\
Hexamethylbenzene & 0.072 & 0.002 & 0.076 & 4.9 \\
\hline & & & & \\
\hline
\end{tabular}

$c$ and the values of $\Delta_{\mathrm{k}}$ to $k_{\mathrm{ij}}$ data from compounds where the actual value of $\boldsymbol{k}_{\mathrm{ij}}$ had already been determined from experimental $\mathrm{CO}_{2}$ solubility data. The $\Delta_{k}$ values were determined for a large base set that consisted of all of the organic compounds in Table 1, and a small base set that contained all of the compounds in the large base set except o-hydroxybenzoic acid and 2,5-xylenol.

\section{RESULTS AND DISCUSSION}

The $k_{\mathrm{ij}}$ values in this paper were determined for solid solutes only. Data on liquids are excluded because the above theoretical model does not apply to liquid solutes. The saturation pressure of a pure solid solute phase depends on pressure as described by the Poynting factor given in the theoretical section; the saturation pressure of a liquid solute phase varies with system pressure in a different manner because the liquid phase contains an amount of the supercritical solvent that varies with system pressure in a manner similar to that described by Henry's law. A $k_{\mathrm{ij}}$ value of 0.071 was 
calculated for liquid phenol at $333 \mathrm{~K}$, which is significantly different from the value of 0.099 calculated for solid phenol at $309 \mathrm{~K}$.

Table 2 compares the values of $k_{\mathrm{ij}}$ which were calculated using experimental solubility data to the values of $k_{\mathrm{ij}}$ predicted from the large base set group increments. The maximum error was $17 \%$. The average absolute error was 6\%. Figure 1 displays $k_{\mathrm{ij}}$ (predicted) vs. $\boldsymbol{k}_{\mathrm{ij}}$ (actual), showing a relatively good correlation. The value of $\mathrm{R}^{2}$ for the multiple regression was 0.907 .

Uncertainty in the $k_{\mathrm{ij}}$ values that were fitted to experimental data comes from several sources. Error in measured solubility data, especially systematic error, would be a significant source. The value of the critical temperature is particularly important; a 5\% error in $T_{c}$ can produce an error of 0.04 in $k_{\mathrm{ij}}$ (if $\mathrm{T}_{\mathrm{c}}$ is estimated, errors in $\mathrm{T}_{\mathrm{c}}$ approaching $5 \%$ are possible for large complex compounds). The value of $k_{\mathrm{ij}}$ is also sensitive, to a lesser extent, to $\omega$ and $\mathrm{P}_{\mathrm{c}}$, in that order. Error in the sublimation pressure can also have a significant effect; error in sublimation pressure is especially large for compounds of very low volatility, such as anthracene, phenanthrene, and pyrene. Reported values of sublimation pressure for compounds such as these often differ significantly. For these reasons, many of the $k_{\mathrm{ij}}$ values calculated are somewhat uncertain. In most cases, the actual uncertainty in the $k_{\mathrm{ij}}$ value is much larger than the standard deviation given in Table 2.

The same holds for the group increments displayed in Table 3, most of which are zero within the standard deviation (the carboxyl group is a significant exception). When o-hydroxybenzoic acid and 2,5-xylenol were removed from the regression, the new group increments (those of the small base set) differed significantly from the group increment values of the large base set, but the values of the group increments from the small and large base set agree within one standard deviation. The respective values of the regression intercept (c), however, disagree by a bit more than one standard deviation.

The group increment of largest magnitude is the carboxyl increment. $\Delta_{k}(\mathrm{COOH}$, large set) $=-0.063 \pm 0.024$, and $\Delta_{k}(\mathrm{COOH}$, small set $)=-0.044 \pm 0.016$. Benzoic acid and o-hydroxybenzoic acid both have small values of $k_{\mathrm{ij}}$ compared to the rest of the compounds in the large base set, and this has held true for most of the carboxylic acids considered in our research.

Displayed in Figure 2 are solubility isotherms as functions of pressure for benzoic acid, which were calculated from the Peng-Robinson equation using the value of $\boldsymbol{k}_{\mathrm{ij}}$ predicted from the group increments of the large base set. (Benzoic acid is a member of the large base set). Included for comparison are experimental solubility isotherms. It is apparent that the Peng-Robinson model exhibits correct trends with respect to changes in temperature and pressure. At low pressure (below 140 bars), both the predicted and experimental solubility decrease when temperature is raised, reflecting a decrease in solvent density, and at high pressure (above 150 bars), both the experimental and calculated values rise with temperature, perhaps due to the increase in the sublimation pressure of benzoic acid. Overall, the agreement between the experimental and calculated solubilities is quite good.

Figure 3 similarly compares experimental and predicted supercritical solubility isotherms for 2,5-xylenol and o-hydroxybenzoic acid. The predicted isotherms were calculated from the PengRobinson model using an estimated value of $k_{\mathrm{ij}}$ obtained from group contribution on the small base set. These two compounds were not in the small base set, so in this case, the solubility calculation 


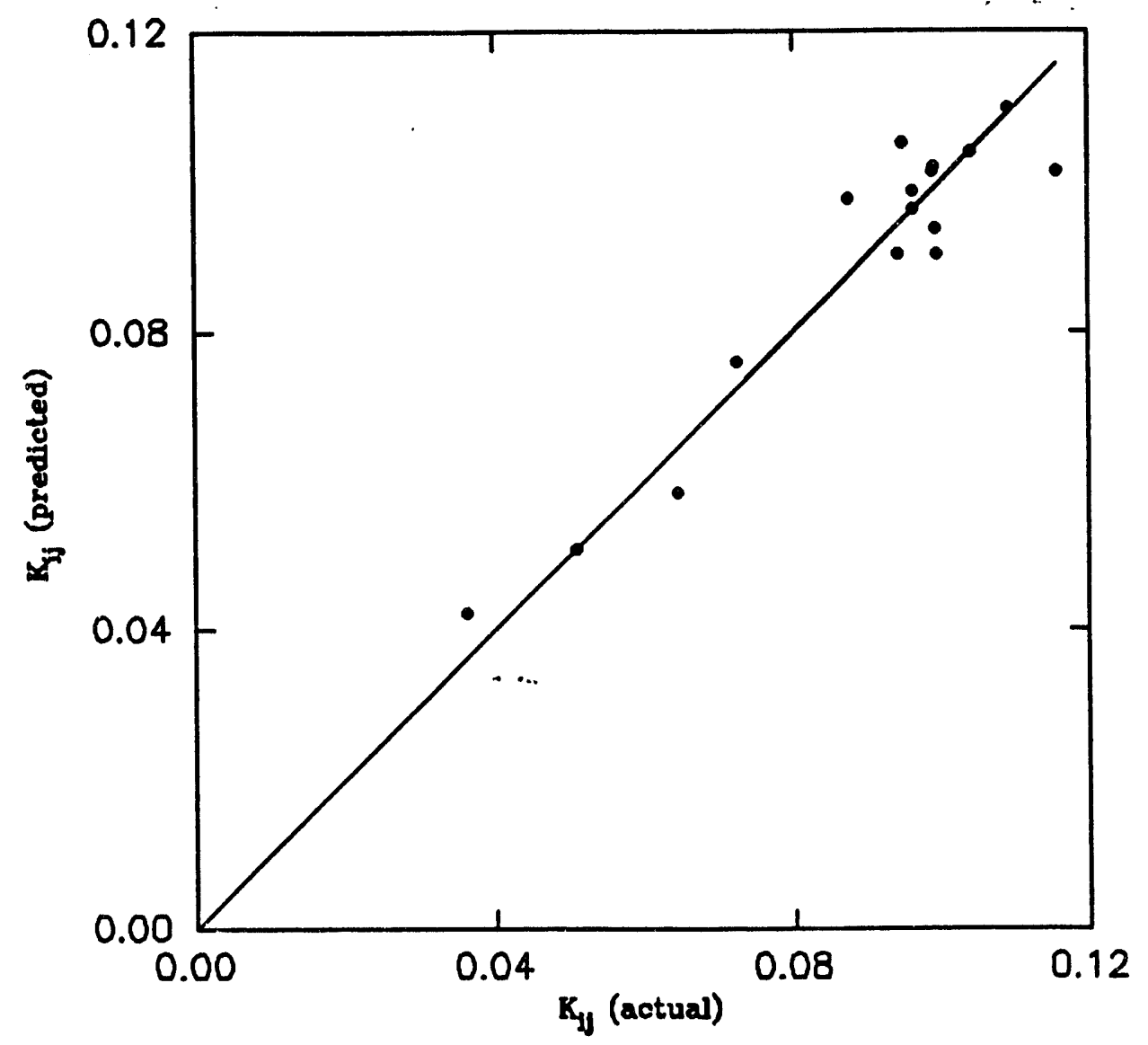

Figure 1. Display of $k_{i j}$ (predicted) vs. $k_{i j}$ (actual), showing a relatively good correlation. 
Table 3. Group increments for $k_{\mathrm{ij}}$ prediction.

\begin{tabular}{|c|c|c|c|c|c|}
\hline & & \multicolumn{2}{|c|}{ Large base set } & \multicolumn{2}{|c|}{ Small base set } \\
\hline & & $\begin{array}{c}\text { Group } \\
\text { increment }\end{array}$ & $\begin{array}{l}\text { Standard } \\
\text { deviation }\end{array}$ & $\begin{array}{c}\text { Group } \\
\text { increment }\end{array}$ & $\begin{array}{l}\text { Standard } \\
\text { deviation }\end{array}$ \\
\hline$-\mathrm{CH}=$ (ring) & & 0.002 & 0.005 & -0.001 & 0.006 \\
\hline -CH2- (ring) & & 0.007 & 0.013 & 0.002 & 0.015 \\
\hline$=\mathrm{C}<$ (ring) & & 0.002 & 0.003 & 0.002 & 0.004 \\
\hline$-\mathrm{CH} 3$ & & -0.002 & 0.009 & -0.006 & 0.010 \\
\hline$-\mathrm{CH}<$ & & -0.013 & 0.030 & 0.001 & 0.034 \\
\hline$-\mathrm{OH}$ (aromatic) & & 0.016 & 0.014 & 0.004 & 0.019 \\
\hline$-\mathrm{COOH}$ & & -0.044 & 0.016 & -0.063 & 0.024 \\
\hline$>\mathrm{CO}$ (ring) & & -0.019 & 0.008 & -0.025 & 0.010 \\
\hline Intercept (c) & & 0.074 & 0.010 & 0.101 & 0.010 \\
\hline R Squared & $\therefore$ & 0.907 & & 0.919 & \\
\hline No. of Observations & & 16 & & 14 & \\
\hline Degrees of Freedom & & 7 & & 5 & \\
\hline
\end{tabular}

is a genuine prediction. For both compounds, the agreement between the measured and the predicted solubilities is quite good. For each compound, three isotherms are displayed. The middle one is calculated with the predicted value of $k_{\mathrm{ij}}$ and the others are calculated with the predicted $k_{\mathrm{ij}}$ $\pm 20 \%$. It is apparent, especially in the case of 2,5-xylenol, that as pressure increases the predicted solubility becomes more sensitive to changes in $k_{\mathrm{ij}}$.

Experimental values of $T_{c}$ and $P_{c}$ of 2,5-xylenol were available for the solubility prediction, but estimated values of $T_{c}$ and $P_{c}$ had to be used for predicting the solubility of o-hydroxybenzoic acid. The value of $k_{\mathrm{ij}}$ for 2,5-xylenol predicted from the small base set agreed closely with the known value, but the value for o-hydroxybenzoic acid predicted from the small base set differed by $33 \%$ from the value calculated from experimental data. (The actual value of $k_{\mathrm{ij}}$ for o-hydrozybenzoic acid has significant uncertainty, however, since, for o-hydroxybenzoic acid, the critical properlies were estimated and the sublimation pressure is low).

This research has investigated using experimental supercritical solubility, a value of $k_{\mathrm{ij}}$ obtained from a group contribution method, and experimental sublimation pressure to predict physical properties of the solutes such as $T_{c}, P_{c}$, and $\omega$, adjusting these parameters to minimize the objective 


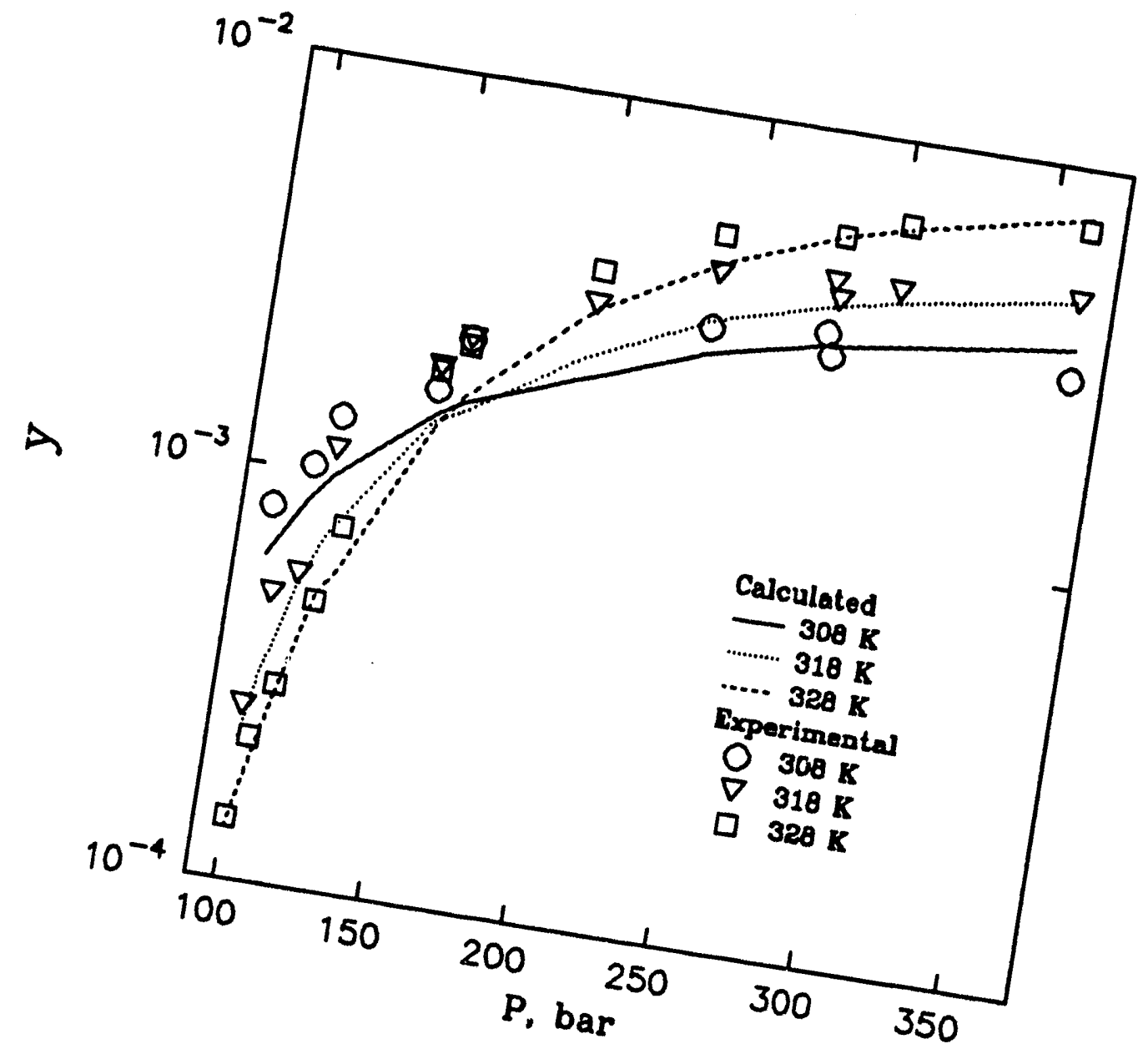
was predicted by group contribution Solubility 


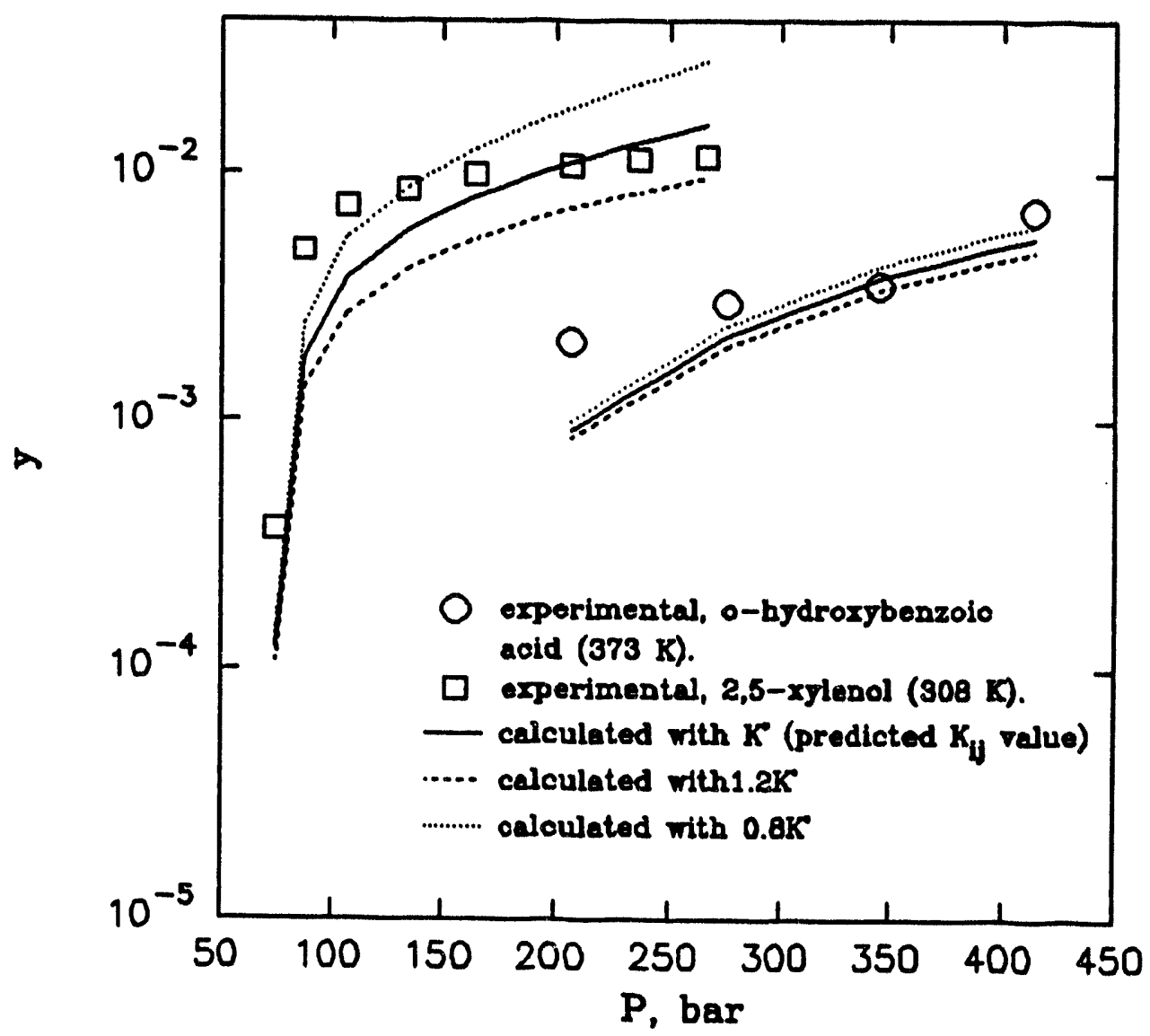

Figure 3. Comparison of experimental and predicted supercritical solubility isotherms. 
function defined earlier. Using five points of solubility data at a single temperature, fairly good estimates were obtained for $T_{c}$ and $\omega$ of naphthalene and phenol. The error for the predicted $T_{c}$ was about $3 \%$. This method could be useful, especially for large, complex compounds or for compounds that decompose much below their critical temperatures, whose critical properties may be impossible to measure and difficult to predict reliably from chemical structure. Further testing of the model should be of interest.

In a previously-published grci!) contribution method for predicting $\boldsymbol{k}_{\mathrm{ij}}$, complex groups such as the phenyl group were used, and $i \cdot c$ lack of $k_{\mathrm{ij}}$ data the contributions of certain groups were assumed to be identical. In the present $g r^{\prime}$ up contribution method, more actual $k_{\mathrm{ij}}$ data is available, and the increments of certain groups can be distinguished; in addition, fundamental, simple groups are used and complex groups are avoided, as in the widely-accepted group contribution methods for predicting critical properties. (The present method assumes, however, that the $=\mathrm{C}$, (ring) and $=\mathrm{C}<$ (fused ring) contributions are the same -- these groups are distinguished in some group contribution methods ${ }^{22}$ ).

To improve the accuracy and to increase the scope of this group contribution method, more $k_{i j}$ values for diverse organic compounds are required. At present, a few of the group increments have been determined from only a single compound's $k_{\mathrm{ij}}$ value, and they are therefore uncertain. With more data, the group increments would represent an average over many compounds. One successful group contribution method ${ }^{22}$ for predicting critical properties uses 35 groups and has a base set of 199 compounds, a nearly 6:1 compound-to-group ratio. With the present lack of $k_{\mathrm{ij}}$ data, the compound-to-group ratio of the $k_{\mathrm{ij}}$ group contribution method unfortunately must be much smaller.

\section{CONCLUSIONS}

It was found that a group contribution method based on the structure of simple aromatic compounds can do a good job at predicting $k_{\mathrm{ij}}$. The presence of carboxyl group in a solute molecule appears to cause a large decrease in $k_{\mathrm{ij}}$. Using Van der Waals mixing rules and an estimate for $\boldsymbol{k}_{\mathrm{ij}}$ determined by group contribution, the Peng-Robinson model is moderately successful for predicting supercritical solubility of the aromatic compounds considered.

\section{ACKNOWLEDGMENT}

This work was support by a contract from DOE Idaho Field Office under the Office of Technology Development's Innovative Technology Development Program.

\section{REFERENCES}

1. D. F. Williams, Chem. Eng. Sci., 36, 1981, 1769.

2. M. E. Paulaitis, V. J. Krukonis, J. R. DiAndreth, and R. C. Reid, Rev. Chem. Eng. 1(2), 1982, 179.

3. K. A. Larson and M. L. King, Biotechnol. Prog. 1986, 2, 73. 
4. M. A. McHugh and V. J. Krukonis, Supercritical Fluid Extraction: Principles and Practice, Butterworths, Boston, MA, 1986, pp. 9-10.

5. J. S. Haselow, S. J. Han, R. A. Greenkorn, and K. C., Chao, Equations of State: Theories and Applications, ACS Symposium Series 300, American Chemical Society: Washington, DC, 1986, K. C. Chao and R. L. Robinson, Jr., eds., pp. 156-178.

6. T. E. Carleson, S. Chandra, C. Wai, L. Wai, and S. S. Huang, Supercritical Fluid Engineering Science: Fundamentals and Applications, ACS Symposium Series 514, American Chemical Society: Washington, DC, 1993, E. Kiran and J. F. Brennecke, eds., pp. 66-73.

7. W. J. Schmitt, and R. C. Reid, J. Chem. Eng. Data, 31, 1986, 204.

8. K. D. Bartle, A. A. Clifford, and S. A. Jafar, J. Chem. Eng. Data, 35, 1990, 355.

9. M. McHugh and M. E. Paulaitis, J. Chem. Eng. Data, 56, 1980, 326.

10. R. T. Kurnik, S. J. Holla, and R. C. Reid, Jr. Chem. Eng. Data, 26, 1981, 47.

11. R. A. Van Leer and M. E. Paulaitis, J. Chem. Eng. Data, 25, 1980, 257.

12. M. McHugh and M. E. Paulaitis, J. Chem. Eng. Data, 25, 1980, 326.

13. K. P. Johnston, D. H. Ziger, and C. A. Eckert, Ind. Eng. Chem. Fundam., 21, 1982, 191.

14. Y Iwai, H. Yamamoto, Y. Tanaka, and Y. Arai, J. Chem. Eng. Data, 35, 1990, 174.

15. G. S. Gurdial and N. R. Foster, Ind. Eng. Chem. Res., 30, 1991, 575.

16. I. K. Barker, K. D. Bartle, and A. A. Clifford, Chem. Eng. Commun., 68, 1988, 177.

17. R. M. Stephenson and S. Malanowski, Handbook of the Thermodynamics of Organic Compounds, Elsevier, New York, NY, 1987.

18. CRC Handbook of Chemistry and Physics, 65th ed., R. C. Weast, ed., CRC, Boca Raton, Florida, 1985, pp C 687-688.

19. W. J. Schmitt, et al., AIChE Meeting, San Francisco, CA, 1984.

20. C. L. Yaws, D. Chen, H. C. Yang, L. Tan, and D. Nico, Hydrocarbon Process, 68(7), 1989, 61.

21. E. J. Henley and J.D. Seader, Equilibrium-Stage Separation Operations in Chemical Engineering, Wiley, New York, NY, 1986, appendix 1.

22. K. M. Klincewica and R. C. Reid, AIChE J., 30, 1984, 137. 

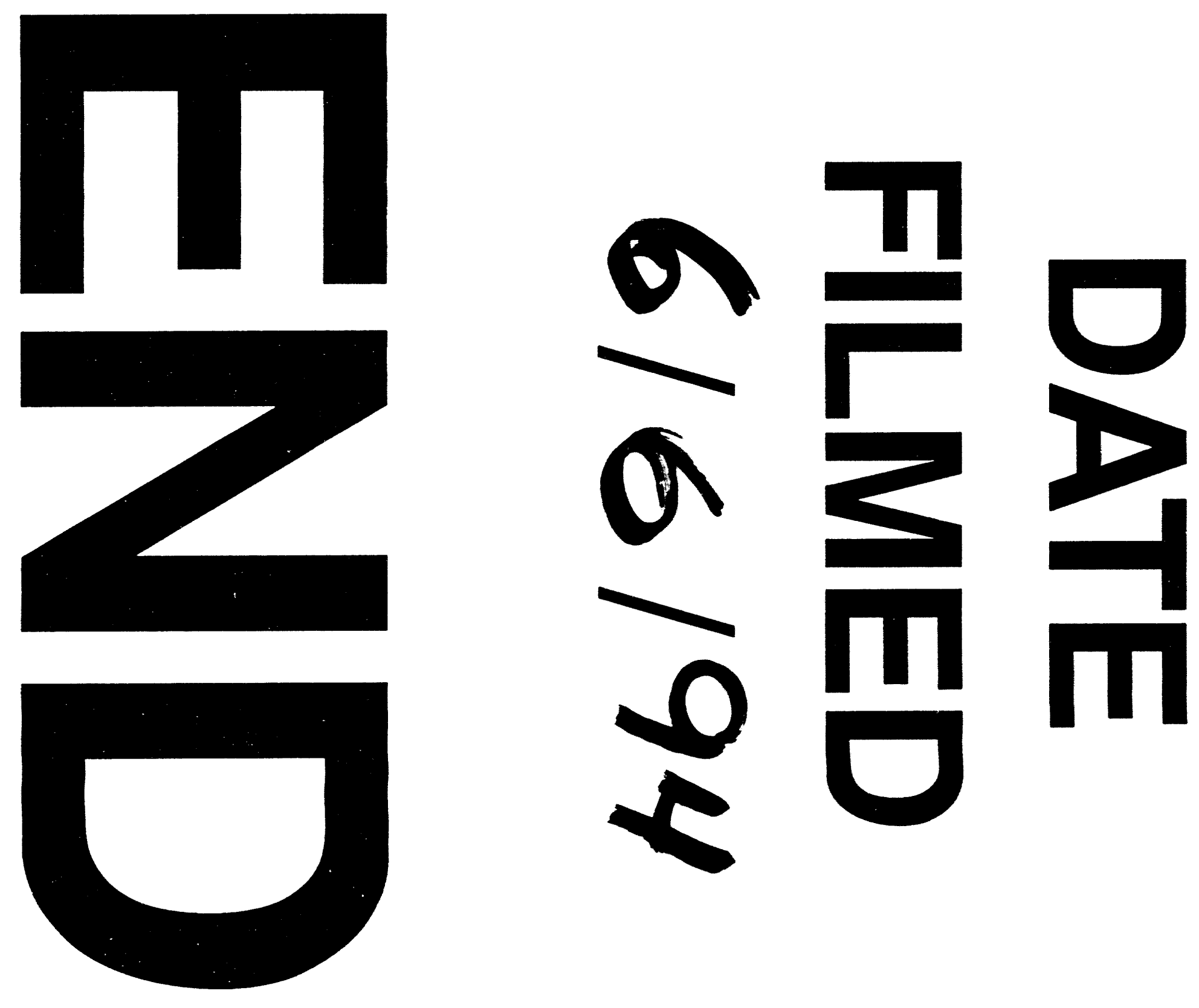
